\title{
Economía social en América Latina: ¿alter o posdesarrollo?
}

\section{Henry Veltmeyer ${ }^{*}$}

Resumen. En América Latina la construcción de la economía social y solidaria corresponde a dos visiones teóricas y diversas prácticas. La primera vertiente es funcional al desarrollo capitalista, bajo las directrices internacionales de organismos financieros y agencias de cooperación que pretenden conciliar el desarrollo urbano y rural con las políticas de ajustes y las estrategias de desarrollo local comunitario basado en el «empoderamiento de los pobres» para conferirle cierta viabilidad al desarrollo capitalista. La segunda vertiente responde a las estrategias anticapitalistas de los movimientos sociales de base que confrontan, en palabras del zapatismo, a la Hidra capitalista y buscan alternativas a fin de generar oportunidades y mejorar la calidad de vida de las clases populares. Ante la pregunta de si la economía social y solidaria es una estratagema neoliberal que defiende al sistema de las fuerzas de resistencia y subversión del movimiento anticapitalista, se analizan la agenda neoliberal, la experiencia del cooperativismo y la autogestión de los trabajadores en la construcción de la economía social; y en particular se examina el caso de Venezuela.

Palabras clave: economía social y solidaria, neoliberalismo, anticapitalismo, América Latina, Venezuela.

*Docente investigador de la Unidad Académica de Estudios del Desarrollo de la Universidad Autónoma de Zacatecas, México.

Traducción del inglés por Georgia Aralú González Pérez y Jesús Alberto Gaytán Castañeda. 


\section{The social economy in Latin America: alter or post-development?}

Abstract. In Latin America, the construction of a social and solidarity economy falls under two theoretical perspectives and various practices. The first approach is functional, via capitalist development, under the international direction of financial institutions and agency of cooperation that aim to reconcile urban and rural development with the adjustment policies and local community development strategies based on the «empowerment of the poor» to confer some kind of legitimacy to capitalist development. The second approach relates to the anti-capitalist strategies of grassroots social movements that challenge, in the words of Zapatis$m o$, the «capitalist Hydra» and search for alternatives to create opportunities and improve the quality of life for the working class. On the question as to whether the social and solidarity economy is a neoliberal stratagem that defends the system from the forces of resistance and subversion by the anti-capitalist movement, we analyze the neoliberal agenda, the experience of co-operativism and worker self-management in the construction of the social economy; and in particular, we analyze the case of Venezuela.

Keywords: social and solidarity economy, neoliberalism, anti-capitalism, Latin America, Venezuela. 


\section{Introducción}

Actualmente, en México y a lo largo de América Latina, muchos grupos están organizando maneras alternativas para asegurar su supervivencia y la de sus comunidades. Existen numerosos ejemplos de personas de las áreas rurales y urbanas que promueven actividades locales, organizan cooperativas y mercados locales de intercambio (de mercancías o bien uso de la moneda local o nacional) dentro de las comunidades. Sin embargo, de acuerdo con David Barkin (2016), en la mayor parte de América Latina esas estrategias alternativas emergen en específico entre los campesinos y grupos indígenas, organizados colectivamente en áreas rurales y al mismo tiempo que forjan economías sociales que evidencian el compromiso con una variedad de modelos de solidaridad social y que Barkin define como «economía ecológica desde abajo». ${ }^{1}$ La proliferación de esas iniciativas, como él argumenta, refleja un reconocimiento de la importancia del desarrollo humano y de la relación de procesos socioeconómicos con el ambiente, una relación recuperada en el concepto indígena de Buen Vivir (o Vivir Bien) — para vivir bien en solidaridad social y armonía con la naturaleza (Acosta, 2012; Gudynas, 2013, 2014).

En estas acciones y experiencias colectivas sobresalen dos concepciones diferentes de la economía solidaria y social: una avanzada como parte de una estrategia en el manejo de las dinámicas complejas del desarrollo urbano y rural, y la otra como parte de la estrategia del movimiento social

${ }^{1}$ La economía ecológica desde abajo, como refiere Barkin, se fundamenta en principios que están ampliamente acordados en el movimiento social popular y se basan en consultas entre organizaciones y comunidades que conforman este movimiento. Se trata de la autonomía, solidaridad, autosuficiencia, diversificación productiva y gestión sustentable de los recursos regionales (Barkin, 2005). 
de base para enfrentar lo que los zapatistas denominan la Hidra capitalista. Ello permitirá encontrar alternativas que brinden más oportunidades y una mejor calidad de vida que la ofrecida por el modelo económico capitalista reciente. La idea es que las estrategias ideadas por las organizaciones internacionales y las fuerzas involucradas en el proyecto de cooperación internacional y desarrollo, que comprende una estrategia de desarrollo local comunitario enfocado en el «empoderamiento de los pobres» (movilizando su capital social para el autodesarrollo, a fin de que ellos «posean» su propio desarrollo), se diseñan como mecanismos de ajuste que son funcionales en la continuación del capitalismo. Desde una perspectiva izquierdista, sin embargo, ¿esta estrategia también puede ser vista como una estratagema neoliberal que defienda al sistema de las fuerzas de resistencia y subversión del movimiento anticapitalista?

El argumento del presente trabajo es que la aparente vitalidad de los esfuerzos desplegados en la región para construir una economía social y solidaria derivan del hecho de que ésta es funcional para el capitalismo y el movimiento anticapitalista. En efecto, no se trata de determinar cuál interpretación es superior para explicar la dinámica de la construcción de una economía solidaria y social. Pese al supuesto conflicto entre las dos perspectivas teóricas, convergen, se complementan, lo que responde a las preocupaciones de los guardianes del sistema y a las demandas del movimiento anticapitalista.

En principio, se reconstruye la agenda neoliberal de la economía social implementada en los espacios locales mediante la acción colectiva de los «pobres rurales» — según el discurso del desarrollo_ y la política gubernamental. En seguida, se retoma la historia del cooperativismo en la región asociada con el proceso de desarrollo capitalista y con distintas 
experiencias autogestivas de los trabajadores y los posteriores esfuerzos por generar una economía social. Después se sitúa el concepto y los múltiples proyectos de una economía social y solidaria dentro de una estrategia de desarrollo local comunitario. Como se observa, esta estrategia es abordada desde dos perspectivas teóricas y diversas prácticas. El trabajo concluye con una breve discusión del proyecto de una economía social y solidaria en construcción en Venezuela dentro del marco institucional y político de la Revolución bolivariana. No se trata de romantizar o elogiar el logro del proceso (está plagado de obstáculos), sino de mostrar que el proyecto se construye desde arriba y desde abajo.

\section{Eje neoliberal de la economía social}

Los 1980 comenzaron con una contrarrevolución conservadora, un movimiento para detener los beneficios incrementales pero constantes obtenido en décadas anteriores por la clase obrera bajo la égida y dentro de la reforma social-liberal del desarrollo del Estado de bienestar.2 Tanto el movimiento obrero organizado como la lucha por la tierra en el campo, estos últimos en forma de diversos ejércitos de liberación nacional, habían sido derrotados a consecuencia de la represión estatal y una estrategia de desarrollo rural

2 A lo largo de lo que los historiadores han denominado «la edad de oro del capitalismo», pero que podríamos nombrar como «era del desarrollo» (aproximadamente entre los $1950 \mathrm{y}$ los 1970), la principal agencia para el cambio social fue el Estado nación a través de políticas de desarrollo económico y la reforma social. La mano de obra organizada fue otro factor clave, ya que podría negociar convenios colectivos con el capital para mejorar los salarios y las condiciones de trabajo. Sin embargo, en los 1960 y 1970, los regímenes militares comenzaron a surgir como reacción a la izquierda política y los lentos pero constantes beneficios de las clases trabajadoras y productoras en el proceso de desarrollo. 
integral diseñada para apartar a los pobres rurales — las masas de familias campesinas desposeídas forzadas por el desarrollo capitalista de la agricultura a abandonar sus medios de vida rural y las comunidades en el campode la política de confrontación de los movimientos sociales que buscan el cambio revolucionario (Delgado y Veltmeyer, 2016). Esa derrota, junto a la dinámica de la deuda externa acumulada y en expansión, creó condiciones que permitieron al Banco Mundial (BM) y al Fondo Monetario Internacional (FMI), las principales agencias y guardianes del sistema, imponen a los gobiernos de la región un programa de ajustes estructurales en sus políticas macroeconómicas, con lo cual se inicia lo que David Harvey, entre otros, han denominado la «era neoliberal».

Un gran objetivo y la meta propuesta por la reforma política neoliberal —verbigracia, privatización de empresas, desregulación de los mercados, libertad de comercio y flujo de capital de inversión así como descentralización de la administración pública - fue liberar las conocidas «fuerzas de la libertad económica» de las restricciones reguladoras del Estado de bienestar. El resultado inmediato de esas reformas estructurales, sin mencionar un extenso proceso de descapitalización asociado al uso obligatorio de los ingresos de las exportaciones de bienes para atender la deuda externa acumulada, ${ }^{3}$ ha sido ampliamente estudiado. Por ejemplo, el avance del capital en las ciudades y el campo, con la consiguiente destrucción de las fuerzas productivas en la agricultura y la industria, y un virtual colapso e involución del mercado de trabajo, lo cual obligó a la creciente

\footnotetext{
${ }^{3}$ Durante los 1980, América Latina experimentó un bajo nivel de formación de capital, resultado de una política concertada por el BM y el FMI, que se unieron en 1983 para obligar a los países endeudados —especialmente México, Brasil y Argentina - a elevar sus economías al mercado mundial y utilizar sus ingresos de exportación para atender la deuda externa.
} 
masa de migrantes rurales a laborar «por su cuenta» en las calles en lugar de intercambiar su fuerza de trabajo contra el capital por un salario digno. Algunos economistas y sociólogos del Programa Regional de Empleo para América Latina y el Caribe (PREALC) y la Comisión Económica para América Latina y el Caribe (CEPAL) estimaron que en el vórtice de estas fuerzas hasta 80 por ciento de los nuevos empleos generados en los 1980 se formaron en «sector informal» (Portes y Benton, 1987; Tokman y Klein, 1988; Tokman, 1988, 1991).

Teóricos y analistas de la comunidad de desarrollo, aquellos asociados con el proyecto de cooperación internacional en la guerra contra la pobreza global, enfocaron su preocupación y atención no en éstos ni en los cambios estructurales, sino en el deterioro de la condición social de los habitantes de los centros urbanos, muchos de los cuales sustituyeron la pobreza rural por una nueva forma de pobreza (los «nuevos pobres» como se les llamó en las estadísticas). El diagnóstico de lo que el cambio en el nuevo orden mundial había provocado — de 40 a 44 por ciento en la década de 1980 - se reflejaba en la frase «una década perdida para el desarrollo».

Lo que estaba perdido, casi del todo, en las diversas reflexiones teóricas sobre dicho proceso - el avance del capital y el retiro del Estadofue la respuesta estratégica y política de los pobres urbanos, ${ }^{4}$ misma que se presentó de dos maneras. Una fue la formación de comedores populares y

${ }^{4}$ Las respuestas de los pobres de las zonas rurales eran diferentes (véase Delgado y Veltmeyer, 2016). Mientras que muchos se ajustaron a las fuerzas del desarrollo capitalista (proletarización, globalización, modernización, urbanización) tomando las vías de desarrollo de la migración y el trabajo abiertas por las agencias de desarrollo, otros optaron por el camino de la resistencia colectiva organizada y otros más se volvieron hacia lo que resultó una economía social basada en las relaciones de solidaridad social, lo que un economista chileno adscrito al PREALC conceptualizó en su momento, a mediados de los 1980, como una «economía solidaria» (Razeto, 1988, 1993). 


\section{HenRy VeLtMEyer}

diferentes acciones colectivas y organizaciones solidarias para ayudar a los pobres a hacer frente a las fuerzas de desarrollo capitalista y sobrevivir en las nuevas condiciones (Petras y Leiva, 1994). Esa respuesta, que en algunos casos condujo a la formación de una vibrante economía social dentro de barrios marginales de ciudades en expansión en la periferia latinoamericana - para citar un estudio de Mike Davis (2006) — estaba particularmente avanzada en Chile y Perú, así como en México, donde un terremoto de 8.0 grados en la escala de Richter acabó con la vida de alrededor de 10 mil personas ${ }^{5}$ y tuvo un impacto dramático en la proliferación de organizaciones no gubernamentales (ONG) que incursionaban en el vacío de un Estado en retirada y en la construcción de una economía social sustentada en la autoayuda, el apoyo mutuo y la solidaridad social. ${ }^{6}$

La construcción de una economía social fundamentada en relaciones de solidaridad social, 7 y el surgimiento y expansión de la «sociedad civil» basada en la asociación de un tipo de ONG, derivó de la convergencia de distintas fuerzas; sin embargo, ésta fue sólo una de varias respuestas a esas fuerzas y condiciones cambiantes. Otra fue la expansión de las protestas y resistencias. A finales de los 1960 y gran parte de la década de 1980, tales protestas y resistencias contra la agenda de reformas neoliberales — entonces se llamaba

${ }^{5}$ Los informes han contabilizado de entre 5 mil y 30 mil (reclamados por varios grupos de ciudadanos) a 45 mil muertos reclamados por el Servicio Sismológico Nacional (Crisp, 1998:150); no obstante, la cifra más citada es aproximadamente de $10 \mathrm{mil}$, si bien es alto como un número absoluto (Campos, 19 de septiembre de 2005).

${ }^{6}$ Pese a que el número total de «asociaciones voluntarias privadas» u ONG a comienzos de los 1980, en el umbral de la era neoliberal, podría ser de cientos, y se estima que a mediados de los 1990, a una década en la era neoliberal, en América Latina podían numerarse en decenas de miles. Sobre la dinámica de estas ONG frente a los movimientos sociales, véase Veltmeyer (2007). ${ }^{7}$ En teoría, una economía social y la acumulación de capital social sólo pueden darse en condiciones de una cultura de solidaridad, que por lo normal existen en las comunidades rurales, especialmente en las que forman los campesinos indígenas (Durston, 1998). 
«protestas del FMI»— eran espontáneas y desorganizadas (Walton y Ragin, 1990). ${ }^{8}$ Su principal objetivo eran las medidas de austeridad dictadas por el FMI, incluyendo recortes en el gasto público, eliminación de los subsidios a servicios públicos y utilidades que elevaban el costo del transporte, combustible, electricidad, agua, alimentos, más allá del alcance de los pobres rurales. ${ }^{9}$ Durante la década de 1990 la resistencia, cada vez más dirigida contra la agenda neoliberal del BM de reforma estructural, en lugar de las medidas de austeridad del FMI, se tornó más organizada. La agencia y los agentes de esta resistencia fueron nuevos movimientos sociales formados en el medio rural por campesinos, trabajadores rurales sin tierra o trabajadores semiproletarizados y comunidades indígenas (Petras y Veltmeyer, 2009). Esa nueva

${ }^{8}$ Aunque en 1983 se combinaron en lo que se conocía como «programa de ajuste estructural», debía distinguirse entre las «reformas estructurales» impulsadas por el BM (privatización, liberalización, desregulación, descentralización) y las medidas de austeridad impuestas por el FMI como condición para acceder al capital público. En la década de 1980 la resistencia se llevó a cabo en respuesta a medidas de austeridad prescritas por el FMI, mientras que en la década de 1990 el objetivo central de ésta fueron las reformas estructurales más profundas del Banco. Respecto al primer caso, surge en Venezuela el caracazo, protesta callejera contra estas reformas del FMI que derivaron en aumentos en el precio de la gasolina y el transporte; comenzó el 27 de febrero de 1989 y resultó en la muerte de cientos de manifestantes, incluso miles según algunas cuentas (Uppsala Conflict Data Program Conflict Encyclopedia, Venezuela, Violencia unilateral, Gobierno de Venezuela-, http://www.ucdp.uu.se/gpdatabase/gpcountry.php?Id=167\&regionSelect=5-Southern_Americas\#). El caracazo fue quizá la razón por la que la agenda neoliberal de reforma no se implementó plenamente, mientras que en Perú, Argentina y Brasil — los tres países principales que habían eludido la agenda de reformas neoliberal—aceptaron la segunda generación de reformas estructurales en los 1990. ${ }^{9}$ En Argentina, los recortes prescritos por el FMI en el gasto social culminaron en fuertes protestas y huelgas en 2000. Por su parte en Bolivia, un préstamo del FMI condicionado a la privatización de los servicios de agua llevó a un aumento de 200 por ciento en los precios del agua, lo que provocó protestas generalizadas. En Ecuador, el préstamo del FMI aprobado en 2000 requirió una reducción del gasto público, la moderación salarial, la eliminación de los subsidios, las reformas en el mercado de trabajo y el sector petrolero y la privatización. Miles de manifestantes salieron a las calles en respuesta y los trabajadores hicieron una huelga general contra las continuas reformas económicas exigidas por el FMI. 


\section{HenRy VeLtMEyer}

ola de movimientos sociales contra el avance del capital y la política neoliberal del gobierno comenzó en Ecuador con un levantamiento en 1990 orquestado por la Confederación de Nacionalidades Indígenas del Ecuador (Conaie), una confederación de varias docenas de nacionalidades indígenas (Petras y Veltmeyer, 2013).

Luego de la irrupción de la Conaie y de otros movimientos campesinos e indígenas en la región, especialmente el Ejército Zapatista de Liberación Nacional (EZLN), ${ }_{10}^{10}$ algunos identificaron la década de 1990 como una «edad de oro» de la resistencia, con referencia al poder de estos movimientos para detener la agenda neoliberal de reforma de políticas y poner al neoliberalismo a la defensiva, hasta el punto de provocar su inevitable desaparición. A fines de ese periodo, la agenda neoliberal estaba muerta en las aguas, lo que condujo a una «marea» de cambios de régimen, la aparición de un ciclo progresista en la política latinoamericana que se remonta al activismo de los movimientos de la sociedad campesina en ese tiempo (Petras y Veltmeyer, 2013).

\section{Economía social y movimiento cooperativo en América Latina}

En el contexto latinoamericano, la construcción de una economía social se ha asociado estrechamente con el movimiento cooperativo de principios del siglo XX, incluso más atrás en ciertos casos (Fabra, 1943). No obstante,

${ }^{10} \mathrm{Al}$ describirse como un «ejército de liberación nacional», el EZLN recuerda un periodo de fermento revolucionario en los 1960 y 1970, cuando los principales movimientos sociales de la época se describieron en esos términos. Pero una vez que el movimiento zapatista se estableció después de una erupción inicial en 1994, auguró una «nueva forma» de «producir cambio y hacer política» —el «primer movimiento posmoderno en la historia» (Burbach, 1994). 
empezó a tomar forma y ejercer una influencia de manera positiva en la vida nacional hasta principios de los 1930 con la Revolución mexicana. Esta última condujo a una oleada decisiva en el movimiento cooperativo así como en el sindicalismo, que dejó su impronta en el movimiento cooperativo. ${ }^{11}$ La historia del cooperativismo y el sindicalismo, manifiesto de distintas formas en varios países, también incluye dinámicas de desarrollo local y experimentos de fábricas dirigidas mediante la autogestión de los trabajadores, es decir, eran conducidas por consejos de trabajadores y asambleas de fábricas surgidas en determinados países en el contexto más amplio de lo que podría describirse como lucha de clases.

Cabe referir el caso de Chile bajo el régimen socialista de Salvador Allende (1970-1973), cuando alrededor de 125 fábricas se sometieron a algún sistema de autogestión de los trabajadores, medio controlado por servidores públicos, lo que representó una forma de gobierno parlamentario con sus divisiones políticas de izquierda-centro-derecha; la otra mitad era liderada por las comisiones de trabajadores a nivel de fábrica, organizadas en la línea de los consejos o soviets obreros, al igual que la Comuna de París de la Francia de mediados del siglo XIX.

Por su parte, Argentina experimentó la crisis 2001-2002, cuando los trabajadores se apoderaron de más de doscientas fábricas, defendiéndolas del cierre, protegiendo su empleo y haciendo enormes mejoras a las condiciones laborales, pero sobre todo, concientizando a los trabajadores. La mayoría de las fábricas —Empresas Recuperadas por sus Trabajadores

${ }^{11}$ México, Argentina y Brasil podrían ser considerados pioneros del movimiento cooperativo en América Latina, el cual avanzó lentamente durante la primera década del siglo XX. El Hogar Obrero fundado en Argentina en 1905 todavía existe. En Brasil, en los estados de Río de Janeiro y Río Grande del Sur, se inició un fuerte movimiento para formar cooperativas a comienzos del siglo. 
(ERT), como algunos las han nombrado- se organizó como cooperativas autogestionadas por el colectivo de trabajadores (Petras y Veltmeyer, 2002; Montiel, 2005).

En cuanto a la Revolución de 1952 en Bolivia y de Perú en 1967, cuando un grupo de oficiales militares nacionalistas progresistas encabezados por el general Velasco Álvarez tomó el poder y expropió un gran número de minas, fábricas y plantíos, se estableció un sistema de cooperativas industriales (y comunidades) basado en decisiones conjuntas por la dirección y los trabajadores. Aunque rara vez se menciona, el caso de Brasil es fundamental. Actualmente, más de doscientas empresas han sido recuperadas por sus trabajadores, con la primera experiencia de la fábrica de zapatos Makerli en 1991. La Asociación Nacional de Trabajadores y Empresas de Autogestión y Participación Accionaria (ANTEAG) se asentó en 1994 con el objetivo de coordinar los proyectos que fueron materializados en condiciones de crisis y en el umbral del colapso de la industria. Esta asociación cuenta con oficinas en seis estados encargadas de acompañar proyectos de autogestión (se busca la integración con ONG), gobiernos estatales y municipales. ANTEAG considera la autogestión como un modelo organizacional que combina la posesión colectiva de los medios de producción con una autonomía de la toma de decisiones empresariales y la participación activa en la gestión democrática.

El punto crucial de éste y otros experimentos similares del cooperativismo y el sindicalismo es que requieren ser entendidos en el contexto más amplio del desarrollo capitalista, en la historia del capitalismo de la región. Aunque la historia del cooperativismo en América Latina es muy compleja, con una experiencia distinta en cada país y un gran auge en la década de 1930, tiene sentido iniciar con el periodo de posguerra del 
desarrollo capitalista, los 1950 y los 1960, cuando «el desarrollo» como se entiende hoy, es decir un proyecto de construcción nacional y de cooperación internacional, se inventó como un medio para impedir que los países de la periferia del sistema capitalista mundial lucharan para liberarse de las ataduras de la explotación colonialista e imperialista, y que en consecuencia no tomaran una vía socialista de desarrollo nacional; ${ }^{12}$ asimismo, se intentaba mantener a los pobres rurales - las masas de pequeños productores y campesinos despojados de sus tierras en la transición hacia el capitalismo- lejos de los movimientos sociales revolucionarios, a fin de evitar la emergencia de otra Cuba.

La solución teórica de esos problemas, esto es, la resistencia al avance del capital, el socialismo o el comunismo como camino alternativo hacia el desarrollo nacional y la demanda de cambio revolucionario era triple: 1) reforma estatal a nivel de programas sociales (salud, educación, bienestar) y tenencia de la tierra; 2) programa de desarrollo integral comunitario local o rural basado en la agencia del Estado con cooperación internacional y mediado por asociaciones voluntarias privadas, con la participación de ONG u organizaciones de la sociedad civil (OSC) financiadas por las agencias de cooperación internacional (en particular la Agencia de los Estados Unidos para el Desarrollo Internacional [USAID, por sus siglas en inglés]); 3) organización de cooperativas. El gobierno de Estados Unidos y varias agencias de la Organización de las Naciones Unidas (ONU) comisionaron una serie de estudios sistemáticos del movimiento cooperativo y de las experiencias

${ }^{12}$ Hay aquí una interesante convergencia teórica entre el argumento presentado por varios defensores del posdesarrollo a mediados de los 1980 (Escobar y Ferguson en Sachs, 1992) y el argumento propuesto más tarde por Veltmeyer (2005) desde un punto de vista de la economía política marxista muy diferente, con respecto al «desarrollo» como forma de imperialismo y medio de desmovilización política. 
de diversos países (aunque no fue hasta 1985 que la CEPAL y otras agencias incorporaron el cooperativismo en su programa de desarrollo social).

El cooperativismo emergió como una forma de desarrollo local, aunque tenía una historia bastante corta: desde finales de los 1960 a mediados de los 1970 (1967-1974). A pesar de que en muchos países se establecieron cooperativas con diferentes grados de éxito y fracaso — en gran cantidad financiados por el gobierno de Estados Unidos/USAID_-, el movimiento se extinguió porque a menudo las condiciones no eran propicias al cooperativismo y al desarrollo cooperativo. Además, el valor del cooperativismo fue cuestionado por algunos analistas — por ejemplo, Robert Guimaraes, economista brasileño asociado a CEPAL, quien ha hecho una gran contribución al entendimiento de las dinámicas alternativas de desarrollo en América Latina-, que argumentaron que las cooperativas eran una forma ineficaz de organización para satisfacer las necesidades básicas de los pobres y un fracaso como agencias de transformación social (Guimaraes, 1989).

Sobre la base de extensas investigaciones de campo y estudios de caso encargados por el Instituto de Investigaciones de las Naciones Unidas para el Desarrollo Social (UNRISD, por sus siglas en inglés) y coordinados por Fals Borda, conocido teórico colombiano de la acción social, Guimaraes concluyó que las cooperativas no sólo eran una manera poco efectiva de terminar con la pobreza sino que tenían escaso éxito como agencia de transformación social. La conclusión general a la cual llegó el equipo del UNRISD, apoyada por Guimaraes, puede resumirse en cuatro premisas:

1. Las cooperativas no son agentes de cambio, producen pocos beneficios para los sectores más pobres de la sociedad; en realidad, el fortalecimiento de las cooperativas en la mayoría de los lugares ha desembocado en un inexplicable aumento de las brechas de ingresos. 
2. Las cooperativas tienden a reproducir la estructura de las relaciones y condiciones de la comunidad, en lugar de transformarlas.

3. Refuerzan, extienden y profundizan las desigualdades sociales preexistentes, en parte porque los grupos e individuos que están acomodados en la estructura de poder son más propensos a controlar los comités clave y la administración de las cooperativas

4. En los contados casos donde las cooperativas estaban compuestas por campesinos pobres, pese a que se representaban sus intereses, eran manifiestamente incapaces de promoverlos (Guimaraes, 1989:285-286).

En cuanto a las condiciones necesarias o propicias para el desarrollo cooperativo, se incluye una cultura de solidaridad que en el caso de muchas comunidades era y sigue indiscutiblemente ausente(Durston, 1998). O'Malley (2001), entre otros, considera que, con excepción de las comunidades indígenas de Bolivia, Ecuador, México y Guatemala, diversas comunidades rurales en la región están divididas en clases sociales o sujetas a fuerzas que han socavado el sentido de comunidad y la cultura de solidaridad. Bajo tales circunstancias, los campesinos no indígenas por lo general quieren su propia parcela de tierra para trabajarla con fuerza laboral familiar. Además, la penetración de diversas fuerzas de cambio (modernización, empresas privadas y capitalismo), la promoción del sector privado y el mercado por el BM y otras instituciones financieras y agencias de desarrollo, así como una cultura capitalista basada en la propiedad privada, el individualismo posesivo y la empresa privada, se han manifestado en contra del cooperativismo. Asimismo, la mayoría de las cooperativas exitosas, incluso en el sector agrícola, no eran cooperativas de productores o colectivos de trabajadores, sino grupos de comerciantes. En realidad, al menos en México, según las leyes establecidas en ese momento por el gobierno para controlar 
las cooperativas, los miembros sólo podían provenir de la clase trabajadora. Se prohibió tener empleados asalariados, los trabajadores únicamente podían formar cooperativas sindicales de consumidores si la asamblea general de la cooperativa coincidía con la propia unión.

La estrategia de desarrollo dominante no era promover el desarrollo local o comunitario, sino explotar la oferta ilimitada de excedente de fuerza de trabajo rural como una palanca de acumulación de capital, con la intención de alentar a los pobres rurales a adaptarse a las fuerzas de cambio a través de una vía de desarrollo que posibilitara a los gobiernos incorporarlos en el mercado laboral. ${ }^{13}$

Hasta mediados de los 1990, esa era la estrategia dominante, pues el mercado laboral estaba saturado y los mecanismos de migración y trabajo, como una válvula de escape, habían alcanzado límites internos y externos. La destrucción de las fuerzas de producción en la agricultura y la industria propició la formación de un gran semiproletariado de trabajadores rurales sin tierra y de un sector urbano informal, en el cual los migrantes rurales debieron asumir la adversidad en lugar de trabajar por un salario. ${ }^{14} \mathrm{La}$ estrategia se orientó hacia la promoción del desarrollo local basado en la comunidad, con el propósito de capacitar a los pobres para que actuaran

${ }^{13}$ La teoría detrás de esta estrategia la esboza con claridad el BM en su Informe sobre el Desarrollo Mundial 2008 acerca de la «Agricultura para el desarrollo».

${ }^{14}$ Para una elaboración de este punto y un análisis de la formación del semiproletariado en condiciones de capitalismo periférico, véase Delgado y Veltmeyer (2016). La teoría fundamental de Marx y los marxistas fue que la transición hacia la agricultura capitalista conduciría a la desaparición del campesinado y a la formación de un proletariado industrial. Es evidente que eso no sucedió en América Latina. Lo que tenemos en cambio con el inicio de la era neoliberal y la invasión del capital en forma de inversión extranjera directa así como la corporación multinacional es la persistencia del campesinado y la desaparición del proletariado industrial, aunado a la formación de un semiproletariado con un pie en la economía urbana moderna (y capitalista) y el otro en la agricultura campesina y la comunidad rural. 
por sí mismos, a la vez que aprovecharan su capital social, único bien que se consideraba abundante (Atria, Siles, Arriagada, Robison y Whiteford, 2004; Portes, 1998; Solow, 2000).

Con el apoyo de un marco institucional de gobernanza descentralizada se estableció una nueva política social enfocada en la reducción de la pobreza, la cooperación internacional en la formación de microfinanzas y la participación social, es decir, la intervención de la sociedad civil en el proceso de desarrollo. Los pobres rurales debían diversificar su fuente de ingreso familiar, lo que les permitía mantenerse y desarrollar sus comunidades. La solución - una estrategia de supervivencia en lugar de una estrategia de desarrollo local — consistía en combinar varias fuentes de ingreso de los hogares: agricultura, fuerza de trabajo, remesas, financiamiento y proyectos de microdesarrollo así como transferencias monetarias condicionadas del gobierno a los hogares pobres (Kay, 2008).

Dentro de ese contexto, las condiciones fueron favorables no sólo para el crecimiento del cooperativismo sino para la construcción de una economía social complementaria al sector privado dominante de pequeñas, medianas y grandes empresas, y al sector público de las empresas estatales: un tercer sector sostenido por la economía solidaria y un proceso de desarrollo local comunitario sustentado en el capital social y no en la empresa privada y el Estado. La noción de economía solidaria surgió a finales de los 1970 y principios de la siguiente década como un modelo económico que combatiera la pobreza y la desigualdad, además de mostrar una postura sobre la transformación social (Razeto, 1998). Sin embargo, en la segunda mitad de la década de 1990 se convirtió en «el nuevo paradigma de desarrollo» denominado desarrollo inclusivo y sostenible, diseñado para expandir un tercer sector de la economía centrado en el capital social y 


\section{HenRy VeLtMEyer}

una cultura de solidaridad social, que a su vez se apoyó por una forma descentralizada de gobernanza y una nueva política social orientada a la reducción de la pobreza y el empoderamiento de los pobres (Narayan, 2002; Rao, 2002; Rondinelli, McCullough y Johnnson, 1989).

Los economistas de la CEPAL, fundados en una concepción sociocéntrica y neoestructuralista del desarrollo nacional, con base en el Estado (con cooperación internacional y cooperación social), conceptualizaron el nuevo modelo alternativo como un «desarrollo hacia adentro» (Sunkel, 1993), «nuevo desarrollismo» (Bresser-Pereira, 2007, 2009) y «desarrollo inclusivo» (Infante y Sunkel, 2009). ${ }^{15}$ Otros, no obstante, desde una perspectiva de desarrollo local, veían la «economía social y solidaria» desde las organizaciones sociales cimentadas en la comunidad como una manera de «desarrollo inclusivo y sostenible» (Vieta, 2014). En esta parte se hace referencia a un concepto desarrollado por Peter Utting (2015), economista de UNRISD, y en un texto editado por un equipo reunido por la Academia de Economía Social y Solidaria de Campinas, publicado por el Centro Internacional de Formación de la Organización Internacional del Trabajo (OIT). Ambas publicaciones, centradas en explorar las condiciones de ampliación de la economía social y solidaria, se dirigen a espacios y estrategias de creación de capacidades, innovación institucional y estrategias de cambio social en el contexto de las limitaciones internas existentes o fuerzas de oposición.

Además de éstos y otros estudios que ofrecen un panorama «de desarrollo», hay quienes consideran la economía social y solidaria no como un modelo de desarrollo alternativo sino como un movimiento social o una agencia de transformación social, una forma de confrontar a la Hidra

${ }^{15}$ Para un análisis de la conexión entre el neoestructuralismo y el nuevo desarrollismo —el primero como fundamento teórico del segundo— véase Leiva (2008) y Mallorquín (2010). 
capitalista (Comisión Sexta del EZLN, 2015). Un modelo ejemplar y paradigmático de tal fenómeno es el EZLN, que a raíz de la Sexta Declaración de la Selva Lacandona de 2005 construyó una vibrante economía social en los márgenes del sistema capitalista y del Estado mexicano. Aunque a la fecha se carece de un modelo teórico reconstruido de dicha economía, es autónoma y comunal con una significativa participación de base. El apoyo se vislumbra en los esfuerzos colectivos y cooperativos de los miembros de la comunidad no así del mercado o el Estado. ${ }^{16}$

Cabe mencionar que los zapatistas no son los únicos que se rigen bajo esta concepción, tampoco se encuentran aislados de una amplia red de América Latina dedicada a la promulgación de una economía social y solidaria (Coraggio, 2011; Jubeto, Guridi y Fernández, 2014; Pérez de Mendiguren, Etxazarreta y Guridi, 2009; REASRed de Redes de Economía Alternativa y Solidaria, s/f). La visión y la práctica de los zapatistas es anticapitalista y por ende fuera de la mentalidad y el marco institucional de las políticas de la economía y la sociedad imaginadas por teóricos y profesionales de la corriente principal, y de varias corrientes alternativas de desarrollo. ${ }^{17}$

${ }^{16}$ Por varios relatos (conversaciones con activistas eruditos cercanos a la organización), los zapatistas han tenido mucho éxito en la organización de la gobernanza, las escuelas y la atención sanitaria autónomas. Su situación económica ha sido más difícil de estudiar, aunque tienen algunas ventajas por su ubicación en el campo, donde han podido hacerse cargo de la tierra y establecer una gobernanza territorial autónoma.

${ }^{17}$ Es difícil evaluar el desempeño real de la economía construida por los zapatistas dado que no han autorizado tal evaluación. No obstante, se sabe más sobre la organización de lo que los propios zapatistas y varios observadores externos (David Barkin, Peter Rosset y Sergio Rodríguez Lascano, editor de Rebeldía) ven como una economía social y solidaria. Parece que los zapatistas han dividido su territorio en cinco regiones que llaman Caracoles. Dentro de cada Caracol existen varios municipios autónomos. Cada municipio está gobernado por un consejo formado por miembros de la comunidad nominados para servir por dos o tres años. 
Los arquitectos y teóricos del desarrollo de la OIT y otras agencias de desarrollo internacional (incluyendo UNRISD y el Banco Nacional de Desarrollo Económico y Social de Brasil) valoran la economía social y solidaria como una agencia dedicada a la reducción de la pobreza, la inclusión y la transformación social. Ello se palpa al menos a nivel del discurso. Todavía más: se concibe como una válvula de escape, un medio para aliviar las presiones sobre los gobiernos a fin de que reduzcan la pobreza mediante el gasto de ingresos fiscales y las presiones sobre el mercado de trabajo para absorber el exceso de mano de obra rural. En cuanto al cooperativismo, las agencias de desarrollo internacional coinciden en que se trata de una forma importante de organización social en pro de una sociedad de operadores de pequeñas empresas, empresarios y gerentes, en vez de una clase trabajadora con sus demandas y problemas.

\section{Desarrollo local comunitario y economía social}

La duración de la agenda neoliberal, basada en el Consenso de Washington sobre las virtudes del capitalismo de libre mercado fue breve. A finales de los 1980, apenas seis años después, el neoliberalismo era económicamente disfuncional — en lugar de cumplir la promesa de prosperidad

Cada uno de los Caracoles tiene una Junta de Buen Gobierno. Estos consejos se componen de un grupo rotatorio de miembros que provienen de todos los municipios autónomos que corresponden a un Caracol particular. Los representantes municipales sirven de enlace para la retroalimentación entre las comunidades y la Junta de Buen Gobierno. Las decisiones se consultan y se toman por consenso. Los miembros de la comunidad que prestan servicios en las estructuras de gobierno autónomo no son remunerados y alternan frecuentemente para que la gobernanza sea una cuestión de participación popular. 
general, el resultado incluyó una década perdida para el desarrollo- y desestabilizador, lo que generó protestas sociales masivas y resistencias políticas (Veltmeyer y Petras, 2000). En respuesta, algunos arquitectos de la agenda neoliberal y varios guardianes del nuevo orden mundial, como el $\mathrm{BM}$, se reunieron a finales de la década con la intención de forjar un nuevo consenso y construir un nuevo paradigma (Banco Mundial, 2007).

El Posconsenso de Washington se originó por la necesidad de traer de vuelta al Estado y conseguir un mejor equilibrio entre éste y el mercado, así como una forma de desarrollo más «inclusiva» y participativa (Infante y Sunkel, 2009). Existen varias formulaciones del nuevo consenso, incluyendo «ajuste estructural con rostro humano» (UNICEF, 1989), «crecimiento con equidad» (Guimaraes, 1989), «desarrollo desde adentro» (Sunkel, 1993) y «desarrollo inclusivo», sintetizados como el «nuevo desarrollismo» (Bresser, 2007, 2009). No hubo consenso en cuanto al mejor modelo económico, sino un amplio acuerdo de principio sobre distintas necesidades: a) reforma estructural a nivel de política macroeconómica; $b$ ) «nueva política social» dirigida a la reducción de la pobreza; c) formación de capital humano a través de inversiones en educación y salud, pilares básicos de la inclusión social; d) buena gobernanza a manera de descentralización administrativa y participación social (o popular); ${ }^{18}$ e) empoderar a los pobres para que actúen por sí mismos al iniciar un proceso de desarrollo local comunitario (Veltmeyer, 2007).

${ }^{18}$ El llamado a la «participación popular» se originó en la política radical, como un clamor de cambio revolucionario, pero en la década de 1970 se convirtió en un principio de reforma liberal y poco después en un principio fundamental de otro desarrollo. La participación en este contexto fue vista como «el eslabón perdido en el proceso de transformación productiva con equidad» (Boisier et al., 1992; CEPAL, 1990). En el contexto de la programación del desarrollo y del ciclo de los proyectos, la participación se considera una cuestión de principio y, como tal, una cuestión de equidad. Pero para el Banco Mundial también se ve como una cuestión de eficiencia, un modo de mejorar la productividad de los proyectos de desarrollo (Blaikie, 1985). 
Con anterioridad se mencionó que no hubo un acuerdo respecto a cuál modelo sería más apropiado para servir como guía a los formuladores de políticas a fin de implementar la agenda. Los arquitectos del Posconsenso de Washington, reunidos a puertas cerradas en 1989 en busca de una solución, se dirigieron a Gonzalo Sánchez de Lozada, ministro de Planificación de Bolivia en ese momento e ideólogo neoliberal, quien a su vez estaba convencido de que en pocos años asumiría la presidencia. Bolivia serviría como laboratorio experimental, con el propósito de probar la reciente política y construir un nuevo modelo, ${ }^{19}$ cuyo marco institucional se estableció por la administración de Lozada en 1994 bajo la forma de la Ley de Descentralización Administrativa y la Ley de Participación Popular. ${ }^{20}$

Según lo constatan los estudios emprendidos por Fernanda Wanderley y sus asociados en CIDES, dicha legislación no sólo otorgó el marco institucional para la agenda política neoliberal enfocada en el desarrollo local, sino que abrió espacio para la construcción de una economía social y solidaria alternativa. Sin embargo, algunos grupos de izquierda, en concreto aquellos que participaban en la «vieja política»—uso del mecanismo

${ }^{19}$ Sobre la base de la información proporcionada por la Asociación Danesa para el Desarrollo Internacional, el plan de desarrollo resultante especificó tres consideraciones estratégicas. Para avanzar en ellas, el equipo económico del gobierno (encabezado por Sánchez de Lozada, Ministro de Planificación de la época) entró en una serie de reuniones de alto nivel con funcionarios de la comunidad financiera internacional (BM, BID, etcétera), el PNUD y representantes de las más importantes asociaciones de desarrollo de ultramar que operan en Bolivia (como USAID). Estas reuniones se extendieron de 1986 a 1992, meses antes de que Sánchez de Lozada asumiera la presidencia.

${ }^{20}$ Estas leyes se establecieron con clara referencia a una agenda política neoliberal; sin embargo, también fueron una respuesta a las demandas de autonomía territorial y regional así como de acceso y control sobre la tierra y otros recursos productivos por parte de los pueblos indígenas del país y diversas asociaciones cívicas; de igual modo, fue una respuesta a la izquierda para la participación popular. 
electoral y otras trampas de la democracia liberal, por ejemplo los partidos políticos como vía hacia el poder estatal — criticaban el interés del régimen por apoyar y promocionar el desarrollo local basado en la comunidad y la economía social. Ellos, naturalmente, lo consideraron una estrategia neoliberal, y sin duda lo fue. Para otros — los que habían desistido por el cambio social mediante el poder del $\mathrm{Estado}^{21}$ con el objeto de alcanzar una nueva política de desarrollo - fue una oportunidad para construir una economía diferente y una forma alternativa de desarrollo iniciada desde abajo a través de la agencia de las bases (Wanderley, 2015).

El reciente marco institucional creó espacios a nivel local dirigidos a la acción política y la participación de las organizaciones sociales de base en la toma de decisiones respecto a proyectos de desarrollo social en la comunidad. En ese sentido, fue difícil para la izquierda oponerse a esa política de descentralización y participación popular. Dicha política derivó en lo que el BM (Bebbington et al., 2006) denomina «empoderamiento» de los pobres. En Bolivia, la Ley de Participación Popular en la práctica pugnó para debilitar a las organizaciones de solidaridad comunitaria y de clase que tuviesen la capacidad de ir más allá de la comunidad, con la intención de desafiar el poder económico y político, a la vez realizar cambios a nivel nacional; al respecto, véase Veltmeyer (2007).

${ }^{21}$ Una formulación teórica de la nueva estrategia fue la concepción de John Holloway sobre cómo «cambiar el mundo sin tomar el poder del Estado», basada en su interpretación del zapatismo, el pensamiento asociado al movimiento zapatista en Chiapas y articulado por el subcomandante Marcos (Holloway, 2000). Para una variación de esta interpretación del zapatismo véase Burbach (1994). 


\section{Economía social y solidaria en Venezuela}

Más allá del proyecto zapatista y otras experiencias en Bolivia (véase Wanderley, 2015), los experimentos más trascendentales en la creación de una economía social y solidaria se perciben en Venezuela, en el proyecto de creación del socialismo del siglo XXI. Aunque la Constitución bolivariana de 1999 se enfocó en el desarrollo de la capacidad humana, también contenía cierto apoyo al capitalismo. Por ejemplo, mientras se rechazaba el neoliberalismo y se subrayaba la importancia de la presencia del Estado en industrias estratégicas, el plan de desarrollo del gobierno para 2001-2007 fomentó la inversión del capital privado — tanto local como extranjero-, lo que creó una «atmósfera de confianza». A ello se agregó el desarrollo de una «economía social» concebida como una «vía alternativa y complementaria» para los sectores privado y público.

El cooperativismo y las cooperativas desempeñan un papel en esta economía social; no obstante, lo significativo, aun desconcertante — como en la última «actualización» del modelo cubano llamado «nuevas directrices»— es cuán pequeño fue su papel asignado a las actividades de autogestión y de cooperación. Al igual que en las agencias de desarrollo de cooperación internacional, en Venezuela el desarrollo de la economía social parece ser, en esencia, un programa que incorpora el sector informal a la economía nacional. Es prioritario, según el plan de gobierno, «transformar a los trabajadores informales en pequeños administradores». Consecuentemente, las microempresas familiares, las cooperativas y las autogestionadas deberían fomentarse mediante la capacitación, el microfinanciamiento (proveniente de instituciones como el Banco de Desarrollo de la Mujer) y la reducción de la reglamentación y las cargas fiscales. 
Por ende, la economía social debía ejecutar la función que despliega en Brasil y en otras partes: las islas de cooperación alimentadas por los Estados, las ONG, los bancos tipo Grameen y las organizaciones benéficas eclesiásticas que amortiguan los efectos económicos y políticos de la globalización capitalista. Lo anterior mejoraría las situación de los desempleados y los excluidos (la mitad de la clase obrera venezolana en el sector informal). La cuestión aquí es que la economía social no fue concebida como una alternativa al capitalismo, excepto en la medida en que la supervivencia dentro de los rincones del capitalismo global constituye una alternativa. El objetivo no era el socialismo tal como lo entendemos, sino un tipo diferente de capitalismo, es decir, el socialismo visto como una forma distinta, más humana, de capitalismo — basada en la participación popular o social - que asegurara el desarrollo integral de las personas tanto individuales como colectivas.

Existe una diferencia fundamental entre «el desarrollo de la economía social» en el contexto de la Revolución bolivariana (concebida por Hugo Chávez) y la economía social/economía solidaria entendida y promovida por la CEPAL, la FAO, la OIT y las agencias de desarrollo de Cooperación Internacional. En el caso de la primera, la economía social es un mecanismo de ajuste a las fuerzas del desarrollo capitalista, una forma de crear espacios dentro del sistema para la reducción de la pobreza fundamentada en el autodesarrollo sostenible local, el capital social de los pobres y el empoderamiento y la agencia de los marginados, así como maneras de convertir al sector informal en una esfera más productiva del desarrollo económico.

Para los teóricos y arquitectos de la Revolución bolivariana (véase los artículos 62 y 70 de la Constitución de 1999), la economía social o la economía solidaria es analizada desde la óptica del desarrollo humano socialista, 
es decir, «autogestión, cogestión, cooperativas en todas sus formas» como ejemplos de «formas de asociación guiadas por los valores de cooperación y solidaridad mutuas». Con énfasis en una sociedad «democrática, participativa y protagónica», la Constitución bolivariana contiene las semillas de la «economía social» concebida no como un complemento de los sectores públicos y privados dominantes sino como núcleos del socialismo para el siglo XXI, es decir, como un modelo de desarrollo nacional no sólo local, provocado desde abajo y desde arriba.

Las cooperativas y el cooperativismo son esenciales en el modelo. Cualquier forma de desarrollo requiere un marco institucional. El marco del desarrollo humano endógeno socialista que se produce en la Revolución bolivariana se basa en la institución de las Misiones y la Comuna orientada hacia la construcción de nuevas capacidades humanas, prepara a la gente para entrar en nuevas relaciones productivas mediante cursos de cooperación y autogestión. El efecto de este programa de desarrollo fue dramático: el número de cooperativas aumentó de menos de 800, cuando Chávez fue elegido por primera vez en 1998, a casi 84 mil en agosto de 2005.

En enero de 2005, en el Foro Social Mundial, Chávez llamó explícitamente a reinventar el socialismo, algo diferente de lo que existía en la Unión Soviética: «Debemos recuperar el socialismo como una tesis, un proyecto y un camino, pero un nuevo tipo de socialismo, humanista, que pone a los seres humanos y no a las máquinas o al Estado por delante de todo». Seis meses más tarde, argumentó la relevancia de construir un nuevo sistema comunal de producción y consumo, en el cual hay un intercambio de actividades determinado por necesidades comunales y por fines comunales, no únicamente lo que Marx describió como el «nexo de dinero» o el incentivo para ganar dinero, acumular capital: «Tenemos que ayudar a 
crearlo, desde las bases populares, con la participación de las comunidades, a través de las organizaciones comunitarias, las cooperativas, la autogestión y las diferentes maneras de crear este sistema».

Se creó entonces una nueva institución — las Empresas de Producción Social (EPS), que promueven la comparación con las «empresas socialmente responsables» (ESR), identificadas por Betancourt y Sagebien (2013), y otros las identifican como las principales unidades operativas de una economía social y solidaria - y un camino organizativo hacia el logro de un «crecimiento inclusivo».22 De acuerdo con diversas fuentes - las cooperativas existentes se comprometieron con la comunidad en lugar de sólo intereses colectivos, empresas estatales más pequeñas y firmas privadas ansiosas por obtener acceso a negocios estatales y términos de crédito favorables-, esas nuevas empresas de producción social debían comprometerse a atender las necesidades de la comunidad y a incorporar la participación de los trabajadores.

En la reelección de Chávez en diciembre de 2006 se agregó un componente: los consejos comunales (basados en 200-400 familias en barrios urbanos existentes y 20-50 en zonas rurales). Éstos se establecieron para diagnosticar democráticamente las necesidades y prioridades de la comunidad. A partir del cambio de los recursos desde los niveles municipales

${ }^{22}$ Los defensores del «crecimiento inclusivo» lo consideran una forma de desarrollo nacional, una alternativa al «desarrollo inclusivo» concebido dentro del marco neoestructuralista del Posconsenso de Washington. La diferencia entre estos dos «modelos», uno avanzado por los economistas del desarrollo de la CEPAL y otro por una red global de think y tanks y foros de política neoliberales, es que se basa en el «activismo estatal inclusivo» mientras que el otro asigna el papel de «conductor» $\mathrm{o}$ «impulsor» del proceso de desarrollo al sector privado. Un informe de 2012 del Comité Permanente de Asuntos Exteriores y Desarrollo Internacional de la Cámara de los Comunes de Canadá es una formulación paradigmática del modelo de «crecimiento inclusivo» (Canadá, Cámara de los Comunes, 2012). 
hasta el nivel comunitario, se apoyaría a los nuevos bancos comunales dirigidos a proyectos locales; su tamaño permitiría a la asamblea general ser el órgano supremo en la toma de decisiones, en lugar de los representantes elegidos. Además de una transformación de las personas en el transcurso de las circunstancias cambiantes, se conseguiría también la actividad productiva cimentada ahora en las necesidades y propósitos comunales.

Esos consejos se identificaron como la célula fundamental del socialismo bolivariano y la base para un nuevo Estado. «Todo el poder a los consejos comunales», declaró Chávez..$^{23}$ Una «explosión en el poder comunal», designada como la quinta de «cinco motores» que conduce el camino hacia el socialismo. La lógica es la de una profunda descentralización de la toma de decisiones y el poder.

\section{Conclusiones}

En esencia, existen dos perspectivas teóricas sobre la construcción de una economía social y solidaria. La primera se enfoca en una estrategia neoliberal ideada a mediados de la década de 1990 como respuesta a la problemática generada por el funcionamiento del capitalismo en la periferia latinoamericana. En este contexto, la economía social y solidaria se considera un tercer sector, complementario al sector público de las empresas estatales y del sector privado; asimismo, como un mecanismo de reducción de

\footnotetext{
${ }^{23}$ Huelga decir que se trataba de una declaración ideológica de intención política y no de una declaración programática. En la práctica, parece que el poder de los consejos locales se limita estrictamente a las cuestiones de desarrollo local. Aun así, parece que dichos consejos locales logran funcionar incluso con la caída de la macroeconomía —o activamente empujados — a la crisis (Teruggi, 2015).
} 
la pobreza mediante la absorción del excedente de fuerza de trabajo rural atrapada en la economía informal. Lo anterior, funciona como una válvula de escape, una manera de reducir las presiones del gobierno y del mercado laboral.

Una segunda perspectiva tiene su más clara expresión teórica y práctica en la economía social creada por los zapatistas, desde su obligado retorno a la selva para ocultarse por segunda vez, tras un intento fallido de llegar a un acuerdo con el Estado mexicano. En ese sentido, la economía social y solidaria es un agente de transformación social, un espacio de cooperación social y una acción de solidaridad de base dentro de un sistema macroeconómico más amplio, o como un movimiento social pos, anti y no capitalista. Prevalecen dos variantes: en la primera, el cooperativismo puede ser articulado con instituciones del sistema capitalista o socialista más amplio y realizar funciones como las formas alternativas de organización de empresas locales dentro de la economía social (cooperativas) y del sector privado (empresas socialmente responsables). Sin embargo, desde una perspectiva pos o anticapitalista — por ejemplo, la articulada por los zapatistas (Comisión Sexta del EZLN, 2015) — la economía social y solidaria es el núcleo de una forma de sociedad alternativa y emergente de tipo poscapitalista.

Referente a las perspectivas de desarrollo de una economía social y solidaria más allá de varios enclaves de desarrollo local y comunitario —aún se cuestiona la posibilidad de ampliarse y coordinarse de manera que constituyan una alternativa viable y vibrante de desarrollo o incluso una alternativa al desarrollo_ - continúa en debate. El jurado todavía no da por concluido este proceso, la interrogante plantea un estudio más profundo. 


\section{Referencias}

Allison, Dean (ed.) (2012), Driving Inclusive Economic Growth: The Role of the Private Sector in International Development (Report of the Standing Committee on Foreign Affairs and International Development, House of Commons), Ottawa: Public Works and Government Services Canada.

Atria, Raúl, Marcelo Siles, Irma Arriagada, Lindon Robison \& Scott Whiteford (2004), Social Capital and Poverty Reduction in Latin America and the Caribbean: Towards a New Paradigm, Santiago, Economic Comission for Latin America and the Caribbean.

Bebbington, Anthony, Michael Woolcock, Scott Guggenheim\& Elizabeth Olson (2006), The Search for Empowerment: Social Capital as Idea and Practice at the World Bank, West Hartford Conn, Kumarian Press.

Betancourt, Rafael \& Julia Sagebien (julio-septiembre, 2013), «Para un crecimiento inclusivo: empresas no estatales responsables en Cuba», Temas (75), pp. 58-65.

Blaikie, Piers (1985), «Why do Policies Usually Fail?», in The Political Economy of Soil Erosion in Developing Countries, London, Longman.

Borja, Jordi (1987), The Decentralization of the State, Social Movements and Local Management, Santiago, Flacso.

Bresser Pereira, Luiz Carlos (julio-agosto, 2007), «Estado y mercado en el nuevo desarrollismo», Nueva Sociedad (210), pp. 110-25. (2009), Developing Brazil: Overcoming the failure of the Washington Consensus, Boulder, Colorado, Lynne Rienner Publishers.

Burbach, Roger (1994), «Roots of the Postmodern Rebellion in Chiapas», New Left Review, 1(205).

Campos, Yunnuen (19 de septiembre de 2005), «A 20 años del sismo del 85», en http://archive.li/QtrsB 
Coraggio, José Luis (2011), Economía Social y Solidaria. El trabajo antes que el capital, Quito, AbyaYala, en http://www.coraggioeconomia.org/jlc/archivos \%20para\%20descargar/economiasocial.pdf

Crisp, Brian (1998), «Presidential Decree Authority in Venezuela», en John M. Carey \& Matthew Soberg Shugart (eds.), Executive Decree Authority, Cambridge, Cambridge University Press.

Davis, Mike (2006), Planet of Slums, London, Verso.

Delgado Wise, Raúl \& Henry Veltmeyer (2016), Agrarian Change, Migration and Development, Halifax, Fernwood Publications.

Durston, John (1998), Building Social Capital in Rural Communities (Where it Doesn't Exist). Theoretical and Policy Implications of Peasant Empowerment in Chiquimula, Guatemala, Santiago de Chile, United Nations Economic Commission for Latin America and the Caribbean.

Comisión Sexta del EZLN (2015), El pensamiento crítico frente a la Hidra capitalista (vol. 1), http://enlacezapatista.ezln.org.mx/2015/07/13/indice-volumenuno-participaciones-de-la-comision-sexta-del-ezln-en-el-seminario-elpensamiento-critico-frente-a-la-hidra-capitalista

Fabra Ribas, Antonio (1943), The Cooperative Movement in Latin America: its Significance in Hemisphere Solidarity, New Mexico, University of New Mexico Press. Ferguson, James (1994). The Anti-Politics Machine: Development, Depoliticization, and Bureaucratic Power in Lesotho, Minneapolis, University of Minnesota Press.

Guimaraes, Roberto (abril, 1989), «Desarrollo con equidad: ¿un nuevo cuento de hadas para los años noventa?», Economic Commission for Latin America and the Caribbean.

Holloway, John (2002), Change the World without Taking Power: The Meaning of Revolution Today, London, Pluto. 


\section{HenRY VeLtMeyer}

Infante B., Ricardo y Osvaldo Sunkel (2009), «Chile: hacia un desarrollo inclusivo», CEPAL, 10(97), pp. 135-54.

Jubeto, Yolanda, Luis Guridi y Maite Fernández Villa (2014), Diálogos sobre economía social y solidaria en Ecuador: encuentros y desencuentros con las propuestas para otra economía, Bilbao, Instituto Hegoa/Universidad del País Vasco, en http://publicaciones.hegoa.ehu.es/assets/pdfs/318/Dialogos_ sobre_ESS_en_Ecuador.pdf? 14029\%2008778

Kay, Cristóbal (2008), «Reflections on Latin American Rural Studies in the Neoliberal Globalization Period: A New Rurality?» Development and Change 39(6), pp. 915-943.

Leiva, Fernando Ignacio (2008), Latin American Neostructuralism. The Contradictions of Post-Neoliberal Development, Minneapolis, University of Minnesota Press.

Mallorquín, Carlos (2010), «Review of Latin American Neostructuralism: The Contradictions of Post-Neoliberal Development by Fernando Ignacio Leiva», Canadian Journal of Latin American \& Caribbean Studies, 35(70), pp. 275-278.

Márquez, Humberto (2009), «Venezuela: Wound Still Gaping 20 Years after 〈Caracazo»», en http://www.ipsnews.net/2009/02/venezuela-wound-still-ga ping-20-years -after-lsquocaracazorsquo/

Montiel, Juan Domingo (junio-septiembre, 2003), «Apuntes sobre empresas recuperadas por los trabajadores en la Argentina», Trabajo y Sociedad, 5(6). (2005), «Empresas recuperadas por los trabajadores en Argentina», en https://www.gestiopolis.com/empresas-recuperadas-por-los-trabajadores-en -argentina/

Mukendi, Didier (1990), Participación de los sectores pobres en programas de desarrollo local, Santiago de Chile, Fondo de las Naciones Unidas para la Infancia. 
Narayan, Deepa (2002), Empowerment and Poverty Reduction: A Sourcebook. Washington, DC, World Bank.

Pérez de Mendiguren, Juan Carlos, Enekoitz Etxezarreta y Luis Guridi (2009), «Economía Social, Empresa Social y Economía Solidaria: diferentes conceptos para un mismo debate», Papeles de Economía Solidaria (1), en http:// www.economia solidaria.org/files/papeles_ES_1_ReasEuskadi.pdf

Petras, James \& Fernando Ignacio Leiva, with Henry Veltmeyer (1994), Democracy and poverty in Chile: the limits of electoral politics, Boulder CO, Westview Press.

Petras, James y Henry Veltmeyer (2002), «Autogestión de trabajadores en una perspectiva histórica», en Enrique Carpintero y Mario Hernández (eds.), Produciendo Realidad. Las Empresas Comunitarias, Buenos Aires, Topia. (2005), Social Movements and the State: Argentina, Bolivia, Brazil, Ecuador, London, Pluto.

(2013), Social Movements in Latin America: Neoliberalism and Popular Resistance, Basingstoke, Palgrave Macmillan.

Portes, Alejandro (1998), «Social Capital: Its Origins and Applications in Modern Sociology», Annual Review of Sociology (24), pp. 1-24.

Portes, Alejandro y Lauren Benton (1987), «Desarrollo industrial y absorción laboral: una reinterpretación», Estudios Sociológicos, 5(13), pp. 111-137.

Rao, Vijayendra (2002), Community Driven Development: A Brief Review of the Research. Washington, DC, World Bank.

Razeto, Luis (1993), De la economía popular a la economía de solidaridad en un proyecto de desarrollo alternativo, Santiago de Chile, Programa de Economía del Trabajo.

(1988), Economía de solidaridad y mercado democrático (vol. III), Santiago de Chile, Programa de Economía del Trabajo/Academia de Humanismo Cristiano. 


\section{HenRY VeltMeyer}

Rondinelli, Dennis, James McCullough \& Ronald Johnson (1989), «Analyzing Decentralization Policies in Developing Countries: A Political Economy Framework», Development and Change, 20(1), pp. 57-87.

Sachs, Wolfgang (1992), The Development Dictionary: A Guide to Knowledge and Power, London, Zed Books.

Solow, Robert (2000), «Notes on Social Capital and Economic Performance», en Partha Dasgupta \& Ismail Serageldin (eds.), Social Capital: A multifaceted perspective, Washington, DC, World Bank.

Sunkel, Osvaldo (1993), Development from Within: Toward a Neostructuralist Approach for Latin America, Boulder, Colorado, Lynne Rienner.

Teruggi, Marco (20 de octubre de 2015), «Venezuela. Communes or Nothing? Three years since the change of Direction», The Dawn.

Tokman, Victor (1991), El sector informal en América Latina: dos décadas de análisis, México, Consejo Nacional para la Cultura y las Artes.

Tokman, Victor y Emilio Klein (abril de 1988), «Sector Informal: una forma de utilizar el trabajo como consecuencia de la manera de producir y no viceversa», Estudios Sociológicos, 6(16), pp. 205-212.

Utting, Peter (2015), Social and Solidarity Economy: Beyond the Fringe, London, Zed Books.

Veltmeyer, Henry (2005), «Development and Globalization as Imperialism», Canadian Journal of Development Studies, 26(1), pp. 89-106. (2007), On the Move: The Politics of Social Change in Latin America, Toronto, University of Toronto Press.

Veltmeyer, Henry \& Anthony O’Malley (2001), Transcending Neoliberalism: Community-Based Development in Latin America, West Hartford Conn, Kumarian Press. 
Veltmeyer, Henry \& James Petras (2000), The Dynamics of Social Change in Latin America, London, Macmillan Press.

Vieta, Marcelo et al. (2014), Social and Solidarity Economy: Towards Inclusive and Sustainable Development, Curso impartido en la International Labour Organization Academy, Campinas, Brasil.

Walton, John \& Charles Ragin (diciembre de 1990), «Global and National Sources of Political Protest: Third World Responses to the Debt Crisis», American Sociological Review, 55(6), pp. 876-890.

Wanderley, Fernanda, Fernanda Sostres e Ivonne Farah (2015), La economía solidaria en la economía plural: discursos, prácticas y resultados en Bolivia, La Paz, Postgrado en Ciencias del Desarrollo de la Universidad Mayor de San Andrés.

World Bank (2007), Meeting the Challenges of Global Development: a Long-term Strategic Exercise for the World Bank Group, Washington, DC, World Bank. 